Prepared for the U.S. Department of Energy

under Contract DE-AC05-76RL01830

\title{
Concept of Operations for Real-time Airborne Management System
}

JL Barr

HM Orr

RY Taira

February 2013

\section{Pacific Northwest}

NATIONAL LABORATORY

Proudly Operated by Battelle Since 1965 


\title{
DISCLAIMER
}

This report was prepared as an account of work sponsored by an agency of the United States Government. Neither the United States Government nor any agency thereof, nor Battelle Memorial Institute, nor any of their employees, makes any warranty, express or implied, or assumes any legal liability or responsibility for the accuracy, completeness, or usefulness of any information, apparatus, product, or process disclosed, or represents that its use would not infringe privately owned rights. Reference herein to any specific commercial product, process, or service by trade name, trademark, manufacturer, or otherwise does not necessarily constitute or imply its endorsement, recommendation, or favoring by the United States Government or any agency thereof, or Battelle Memorial Institute. The views and opinions of authors expressed herein do not necessarily state or reflect those of the United States Government or any agency thereof.

\author{
PACIFIC NORTHWEST NATIONAL LABORATORY \\ operated by \\ BATTELLE \\ for the \\ UNITED STATES DEPARTMENT OF ENERGY \\ under Contract DE-AC05-76RL01830
}

Printed in the United States of America
Available to DOE and DOE contractors from the Office of Scientific and Technical Information,
P.O. Box 62, Oak Ridge, TN 37831-0062;
ph: (865) 576-8401
fax: $(865)$ 576-5728
email: reports@adonis.osti.gov

\begin{abstract}
Available to the public from the National Technical Information Service, U.S. Department of Commerce, 5285 Port Royal Rd., Springfield, VA 22161 ph: (800) 553-6847 fax: $(703) 605-6900$ email: orders@ntis.fedworld.gov online ordering: http://www.ntis.gov/ordering.htm
\end{abstract}

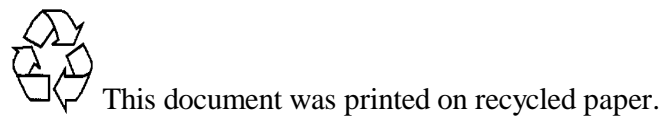




\subsection{Scope}

\subsection{Identification}

This Concept of Operations (CONOPS) document applies to the Real-time Airborne Management System (RAMS) to support emergency operations. RAMS has been utilized with LA County Fire in support of Urban Search and Rescue (USAR) during the 2011 Golden Guardian exercise.

\subsection{Document Overview}

The purpose of this document is to describe the operating concepts, capabilities, and benefits of RAMS including descriptions of how the system implementations can improve emergency response, damage assessment, task prioritization, and situation awareness. This CONOPS provides general information on operational processes and procedures required to utilize RAMS, and expected performance benefits of the system.

The primary audiences for this document are the end users of RAMS (including flight operators and incident commanders) and the RAMS management team. Other audiences include interested offices within the Department of Homeland Security (DHS), and officials from other state and local jurisdictions who want to implement similar systems.

\subsection{System Overview}

The proposed RAMS system consists primarily of an airborne platform and a mobile ground station. The airborne component can be flown over an impacted area to capture aerial pictures with excellent resolution. The aerial camera integrates five digital cameras providing a nadir view and four side-looking orthogonal views. The system is capable of wirelessly transmitting the imagery to the mobile ground stations as a base layer in near real-time for GIS systems to consume. The base layers and imagery can then be transmitted via the internet to emergency personnel to provide infrastructure damage assessment, situational awareness, and providing decision support. A more detailed description of the system is presented in section 5.2.

\subsection{Referenced Documents}

The standards and guidelines used in preparation of this document are listed below.

- Software Engineering Standards Committee of the IEEE Computer Society. IEEE Std 1362, IEEE Guide for Information Technology-System Definitions-Concept of Operations (ConOps) Document, March 19, 1998

This document can be found at the IEEE website. A direct link is provided (http://ieeexplore.ieee.org/xpl/articleDetails.jsp?tp=\&arnumber=761853\&contentType=Standards\&query Text\%3D1362) 


\subsection{Current System or Situation}

\subsection{Background and Objectives}

When a disaster occurs, the impacts can include loss of life, personal injuries, damage to infrastructure and homes, and interruption of utilities. The general public relies on the local and federal governments to respond to these issues as quickly as possible. Rapid and defendable damage assessments allow appropriate disaster declarations to be made quickly, releasing funds to reimburse communities for recovery and restoration actions. RAMS offers the ability to quickly assess damage to infrastructure providing a defendable foundation for credible assessments.

In order for emergency personnel to develop plans for response, they must gain situational awareness or in other words, establish an understanding of the severity of the disaster, extent of any damage, and threats to human health. Once situational awareness is established, it is possible to develop plans and methodically prioritize responses in order of importance. Key to gaining situational awareness is the ability to collect and process information rapidly and accurately. The faster that incident information can be collected and disseminated the more rapidly plans can be developed and responses made. To this end, numerous methods, procedures, and technologies are currently used by government agencies to collect and deliver information necessary to establish situational awareness during disaster events. The purpose of this section is to provide descriptions of the most commonly used methods for collecting and delivering situational awareness data to emergency response personnel.

\subsection{Operational Policies and Constraints}

There are no other constraints beyond those mentioned in Section 3.3. The current methods practiced to collect and communicate situational awareness data have been approved and comply with appropriate operational policies.

\subsection{Description of the Current Situation}

Currently, numerous means are used by government agencies to obtain situational awareness during disaster events. The methods are typically a combination of technologies and procedures. Four of the more common methods are described in this section and are provided below along with a brief description:

- Windshield Surveys - These reports consist of incident and status information observed from a vehicle traveling along a pre-defined route. These surveys, typically performed by the Fire Department, are conducted immediately after a disaster event and often provide the initial information received at emergency operations locations.

A typical method for performing these surveys is as follows:

Prior to any events, map routes are developed with key infrastructure points highlighted. Each Fire Station is assigned a route. These route maps are printed out and a hard copy is followed during the survey. Personnel drive the route and evaluate the key infrastructure points and any other damage of note. If they see damage that should be reported, they fill out a 'Damage Assessment Form'. On the form they record: address, time observed, condition (red or yellow) 
and comments. There are also hazard check boxes for fire, hazmat, gas leak, collapse, number of stories, and additional parameters. After the form is filled out, they continue along the route and note other damage until they are back at the Fire Station. At the Fire Station, only the damage instances that were labeled 'red' are called in via radio to the Battalion Chief. The Battalion Chief may request information on the 'yellow' damage locations depending on the situation.

The benefits of the windshield surveys are:

1. Battalion Chiefs are alerted of only the issues of greatest need. As those issues are addressed they can focus on the next level of issues.

2. Low tech: a pencil, a form, and a radio to call in important damage is all that is required.

3. Does not rely on internet connectivity, cell phone connectivity or landlines, which can be non-operational after a major disaster event.

- Satellite Imagery - High resolution imagery that provides information on the extent of damage to an area. These images also provide valuable information as to road and bridge conditions necessary for rescue and delivery of relief resources.

The images are typically made available at no cost typically via the internet by multiple entities including Humanitarian Information Centres (HICs), Reliefweb, AlertNet, UNITARS [United Nations Institute for Training and Research] Operational Satellite Applications Programme (UNOSAT), and the National Geospatial-Intelligence Agency (NGA). Aside from viewing and/or downloading imagery, little to no work is required by the end user. Initially imagery is useful in assessing the extent of damage; later images can be used in the field to support relief and coordination activities.

The benefits of using satellite imagery are:

1. Large scale imagery provides unique and holistic perspective of an impacted area (scale).

2. Comparing before and after imagery can reveal impacts that might not be initially apparent. For example, in a situation where the devastation is severe, it may be difficult to identify what was at a location before the disaster such as houses, road locations, and other important infrastructure.

3. Imagery is provided at no cost.

4. Imagery can be combined with vector or raster data in a GIS to provide imagery for locations of interest that can be overlaid and aligned with other data sets.

- Forward Looking Infrared (FLIR) Imagery - Images provide extent of hotspots as well as views of regions of interest (ROI) and how they are changing with time. Primarily of use when attempting to locate objects or areas that are higher in temperature than their surroundings. Can also be useful in locating people; however, ability to detect decreases with depth under surface (e.g., building rubble).

FLIR images can be taken via satellite or airborne sensors. Images can be transmitted via the internet, electronically, and in hard copy. Images are most useful when they are geotagged and integrated with other imagery to provide context. 
The benefits of using FLIR images are:

1. Images can be obtained in low light and night-time conditions (Near Infrared)

2. Images can be a valuable asset when planning fire-fighting strategies. Hotspot locations and effectiveness of fire-fighting methods being used can be evaluated over time.

3. When images are referenced to GPS coordinates, they can be integrated with other GIS information to determine proximity of hot spots to sensitive areas such as transformers, hazardous materials, and fuel tanks.

4. When calibrated to provide absolute temperature values, that information is extremely valuable to fire fighters.

5. Can differentiate between a warm human and a colder surrounding, an especially helpful form of contrast for search and rescue.

- Aerial Video - Video cameras mounted in rotorcraft and/or fixed wing aircraft provide a realtime view of the ground. These feeds can be supplied either through government or media assets. By monitoring these feeds it is possible to see events unfold in real-time. The ability to use cameras attached to rotorcraft allows for a stationary or mobile view of an area. Finally, aerial video can be transmitted point to point utilizing antennas. This transmission mode can eliminate dependency on the infrastructure which may be down after a disaster (e.g. internet).

The benefits of using aerial video are:

1. Information available in real-time.

2. The ability to use cameras attached to rotorcraft allows for a stationary or mobile view of an area.

3. Aerial video can be transmitted point to point utilizing antennas. This transmission mode can eliminate dependency on the infrastructure which may be down after a disaster (e.g. internet).

- Social Media - Text and pictures associated with an event are provided by the general public and made available to the general public. Messages may contain the status of a situation; provide warnings or instructions, or even requests for help. Information is typically uploaded to text messaging services (e.g., Twitter, blogs, Facebook) where events are occurring via mobile devices such as cell phones or tablets. Government agencies and the general public must determine what reports are trustworthy. Social media reports are typically viewed as ancillary information and not reported on by news or government agencies until events in the reports can be confirmed.

Due to the popularity of social media, some government agencies have started using these same means to communicate information back to the general public.

The benefits of using Social Media are:

1. Large amounts of information that would typically not be available are reported by and to the public.

2. Personal accounts are reported almost as they happen.

3. Requests for help can be made and potentially acted on by the public before government services can respond.

4. Important and potentially lifesaving information is transmitted rapidly. 
5. Warnings and updates can be provided rapidly.

6. Encourages the public to help each other and fill in the gaps where the government cannot.

7. Can be a good way to communicate when the phone lines are down.

\subsection{Modes of Operation for the Current Situation}

The primary mode of operation for the current systems described in this section is Normal Mode. However, because usage of the systems is associated with emergency response/operations, the systems operate in Normal Mode during emergency or disaster situations. Some of the systems can be operated in other modes as described below:

Windshield Surveys - As noted, windshield surveys are an emergency response protocol, so the Normal Mode of operations occurs during emergency situations. It may also be operated in Training Mode when personnel are learning the system or re-training.

Satellite Imagery - This system is continuously operated in Normal Mode by other government and nongovernment entities. It is not operated by emergency manager personnel; however the imagery can be accessed during and after emergency events. Emergency management personnel may access this system for images during a planning mode in order to get baseline maps for planning and comparison in case of emergency events.

FLIR Imagery - This system is used in Normal Mode during emergency situations and also in a Search and Rescue mode. The Search and Rescue mode may be associated with a large scale emergency where the tool is examining an area for indications that citizens may be trapped and in need of rescue or in situations where a single individual is lost or wanted.

Social Media - This system is operated by the general public continuously in its many forms (e.g., Twitter, Facebook, blogs). Emergency Management personnel will primarily access it during disaster or emergency situations. It may also be used in search and rescue situations to receive information and also to send out requests for information that would be useful in locating lost or wanted individuals.

\subsection{User Classes and Other Involved Personnel}

\subsubsection{Organizational Structure}

\section{Organizational Structure for Urban Search and Rescue}

- $\quad$ Fire Head Quarters, including Command and Control (Fire HQ)

- Battalion

- Fire Station

- USAR Task Force

- Fire Fighters

○ Fire Fixed Wing Pilots

- General Public

- State Emergency Management (State EM)

- FEMA Regional Operations (FEMA)

- National Geospatial Agency (NGA) 


\subsubsection{Interactions among user classes}

\section{N-squared Diagram:}

User classes are listed in bold along the diagonal. Inputs are vertically above/below the user class. Outputs are horizontally left/right of the user class.

\begin{tabular}{|c|c|c|c|c|c|c|c|c|c|}
\hline Fire $\mathrm{HQ}$ & $\begin{array}{l}\text { Tasking, Resource Status, Fire } \\
\text { specific GIS products, general sit. } \\
\text { awareness information (Gen SA) }\end{array}$ & & & $\begin{array}{l}\text { Tasking, NGA Sat } \\
\text { Imagery, Fire specific } \\
\text { GIS products, Gen SA }\end{array}$ & $\begin{array}{l}\text { Tasking (Flight } \\
\text { Routes and } \\
\text { ROIs) }\end{array}$ & & $\begin{array}{l}\text { Resource } \\
\text { Request (Sat } \\
\text { Imagery) }\end{array}$ & & \\
\hline \multirow[t]{3}{*}{$\begin{array}{l}\text { Status of } \\
\text { Battalion's Area }\end{array}$} & Fire Battalion & $\begin{array}{l}\text { Tasking, } \\
\text { Resource } \\
\text { Status, Gen SA }\end{array}$ & & & & & & & \\
\hline & $\begin{array}{l}\text { Status of Fire Station and } \\
\text { surrounding area }\end{array}$ & Fire Station & $\begin{array}{l}\text { Tasking, Resource } \\
\text { Status, Gen SA }\end{array}$ & & & & & & \\
\hline & & $\begin{array}{l}\text { WindShield } \\
\text { Survey Data }\end{array}$ & Fire Fighter & & & & & & \\
\hline $\begin{array}{l}\text { Resource } \\
\text { Requests, Mission } \\
\text { Status }\end{array}$ & & & & USAR Task Force & & & & & \\
\hline FLIR Imagery & & & & & $\begin{array}{l}\text { Fire Fixed Wing } \\
\text { Pilots }\end{array}$ & & & & \\
\hline $\begin{array}{l}\text { Social Media } \\
\text { Feeds }\end{array}$ & & & & & & $\begin{array}{l}\text { General } \\
\text { Public }\end{array}$ & & & \\
\hline \multirow[t]{3}{*}{ NGA Sat Imagery } & & & & & & & State & $\begin{array}{l}\text { Resource } \\
\text { Request (Sat } \\
\text { Imagery) }\end{array}$ & \\
\hline & & & & & & & $\begin{array}{l}\text { NGA Sat } \\
\text { Imagery }\end{array}$ & FEMA & $\begin{array}{l}\text { Resource } \\
\text { Request (Sat } \\
\text { Imagery) } \\
\end{array}$ \\
\hline & & & & & & & & NGA Sat Imagery & NGA \\
\hline
\end{tabular}




\subsection{Justification For and Nature of Changes}

\subsection{Justification of Changes}

\section{High Level Justification}

In the first hours after a disaster as everything is in a state of flux: conditions may still be changing (i.e., ongoing damage), staffing at emergency operations locations is limited as personnel must report in to work with the same personal and transportation challenges as the public does, and the understanding of the situation continually changes as new reports and information is received. It is in this dynamic environment that information must be gathered and processed quickly by the available staff in order to appropriately address issues and develop tactical plans.

As described in previous sections, numerous methods, procedures, and technologies are currently used by government agencies to collect and deliver information necessary to establish situational awareness during disaster events. While these methods have generally proven sufficient, significant improvements can be made. This is especially true in the area of aerial imagery; where more accurate and timely information would expedite the identification of problems (or potential problems), the prioritization of issues to address, and transportation routing for both rescue and resources.

\section{Deficiencies of Current System}

The systems currently used to provide situation awareness during a disaster all provide valuable information critical for developing responses in emergency situations. There are however, issues and limitations associated with each of them, which are presented below:

\section{Windshield Surveys}

1. Because the personnel don't leave their vehicle, only hazards visible from the survey route are reported.

2. The windshield surveys are designed to take no more than 30 minutes. This may not be possible due to road conditions and traffic. Also, personnel responsible for the survey are not supposed to respond to other situations while performing the survey. They can call situations in but are supposed to continue with the survey. In reality, if personnel see a life and death situation, they will act. This slows down the completion and reporting of the survey.

3. The personnel performing the survey are not available to perform other tasks.

4. Whether or not damage should be reported is very subjective and could vary depending on who is performing the survey. Similarly, whether damage warrants a 'yellow' or 'red' label is fairly subjective. This is important because only the 'red' incidents get reported initially.

5. Because the personnel don't leave their vehicle, only hazards visible from route are reported.

6. Nothing is reported until they return to the Fire Station, so damage recorded early in the survey may not be reported for 30 minutes or until the end of the survey.

7. Damage reports are radioed in. After an event, radio traffic is extremely congested.

8. People receiving the reports must rely on verbal comments to decide on how to prioritize resources (i.e., which 'red' incidents should be attended to first?).

\section{Satellite Imagery}

1. There can be a significant time delay in seeing imagery. 
a. Example 1: In Indian tsunami event, the tsunami hit on 12/26/2004. The United Nations Operational Satellite Applications Programme (UNOSAT) did not post its first map until 12/29/2004. The UNOSAT online imagery bank was operational on 01/14/2005.

b. Example 2: In the 2008 flooding incidents in Indiana, requests were made to USGS and imagery data was received in 48 hours.

2. Normally end user has no control over imagery locations.

3. Often provided on web browser or via computer network. This can be problematic if computing resources are not operational.

4. Time of day, smoke, and cloud cover can impact imagery.

5. Resolution: UNOSAT (12 m), Landsat 7 (30m, can be as high as $41 \mathrm{~cm}$ for small areas).

6. Only one view (approximately orthogonal) available for any given satellite and location.

\section{FLIR Imagery}

1. Thermal images are most effective before daybreak to minimize the impact of solar heating.

2. Images must be post processed to GPS coordinates to be integrated with other GIS tools.

\section{Aerial Video}

1. Only one view per camera.

2. It is difficult to combine the video feeds with other information.

3. Difficult to use video feeds with GIS (e.g. converting video feeds to base maps)

4. Cameras have to compromise on either resolution or coverage.

5. Only provides information where cameras are recording and could therefore skew priorities in a similar fashion to that described with windshield surveys.

\section{Social Media}

1. Volume of information received may be overwhelming and difficult to process or sift through to get information pertinent to situational awareness needs.

2. Validity of reports must be viewed as questionable until verified. Verification in some cases may simply be reports from numerous people of the same event.

3. Citizens could potentially put themselves in danger reporting on something when they should be taking care of their safety. 


\subsection{Concepts for the Proposed System}

The following sub-sections provide a description of the proposed RAMS system including the background, objectives, scope, constraints, process/workflow, user classes, personnel, and the required support environment.

\subsection{Background, Objectives, and Scope}

The purpose of the Real-time Airborne Management System (RAMS) is to provide emergency response teams with pertinent information during disaster situations in which critical infrastructure is heavily damaged. RAMS is an airborne platform that can be flown over an impacted area to provide aerial images of those areas. While other technologies that provide aerial images exist and may be currently be in use, the RAMS system provides several significant benefits including: near-real-time pictures with excellent resolution, "side looking" cameras that provide images with depth of field rather than just a top-down view, and the system capability to push imagery out as a base layer in real time for GIS systems to consume and serve to Emergency personnel for situational awareness and decision support.

This ability to deliver current, high resolution aerial images to end users in near real time and in usable formats will be a tremendous advantage to emergency management personnel. It will provide views of impacted areas (including road conditions and electrical infrastructure) much earlier in the response process than is currently possible. In some cases it can be days faster. This amount of time can be significant when related to outcomes of response operations and disaster declarations.

With this access to current aerial imagery, emergency management personnel can locate known areas of concern on maps that display current (i.e., after the disaster) conditions. They can also identify, through road and traffic conditions, the best routing to reach these areas for search and rescue or the delivery of resources. Additionally, through visual inspection of the imagery, they will have the ability to identify other concerns that should be addressed, such as physical status of critical infrastructure (e.g. the ability to quickly determine the exact locations of downed power lines).

\subsection{Description of the Proposed System}

The proposed RAMS system consists primarily of an airborne platform and a mobile ground station. The airborne component can be flown over an impacted area to capture aerial pictures with excellent resolution. The system is capable of wirelessly transmitting the imagery to the mobile ground stations as a base layer in near real-time for GIS systems to consume. The base layers and imagery can then be transmitted via the internet to emergency personnel to provide valuable added information in establishing situational awareness and providing decision support.

\subsubsection{Major system components}

There are two major hardware components that comprise the system as described below:

- The airborne platform is installed on a fixed wing aircraft similar to the on in figure 5.1. It consists of a high resolution five camera system mounted to the outside of the plane. The five cameras are aimed with one looking nadir and four looking in each of the four cardinal oblique 
directions. Hardware is also installed inside the aircraft for disc storage and communication to satellites and ground stations. This hardware includes an Applanix Position and Orientation System (POS) which includes both a Global Positioning System (GPS) antenna and an Inertial Measurement Unit (IMU). This equipment must be fitted and calibrated to each aircraft. Ideal height for capturing images is 5000' with a low ceiling of 1200'.

- The ground station equipment fits in a set of pelican cases (Fig. 5.2) is transported in a small trailer or vehicle that must remain in line of site of the aircraft. It is responsible for receiving images from the airborne platform and making the images available via the internet in near realtime.

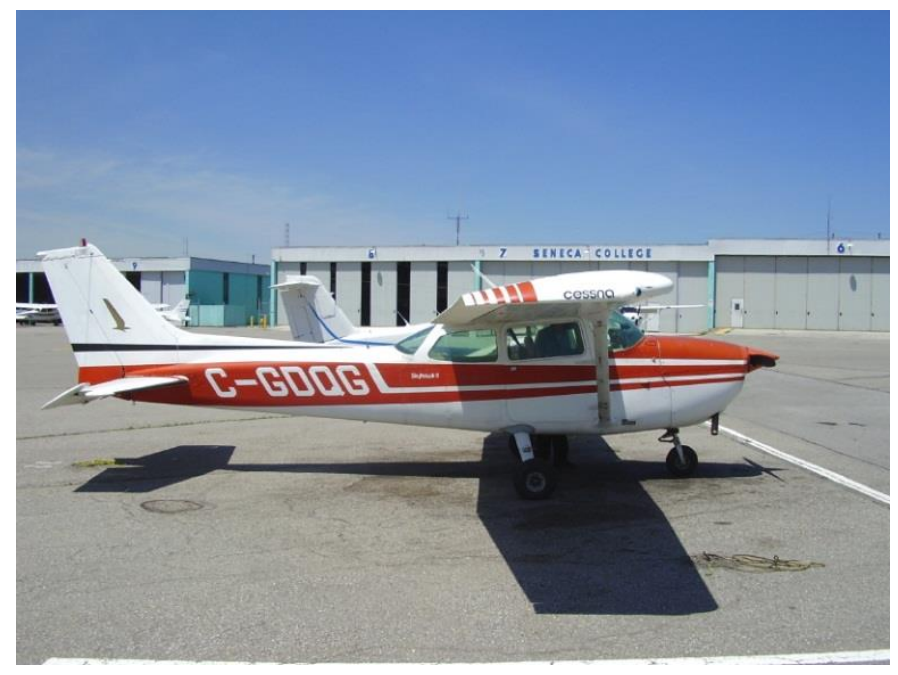

Figure 5.1. Cessna aircraft representative of those which RAMS can be mounted

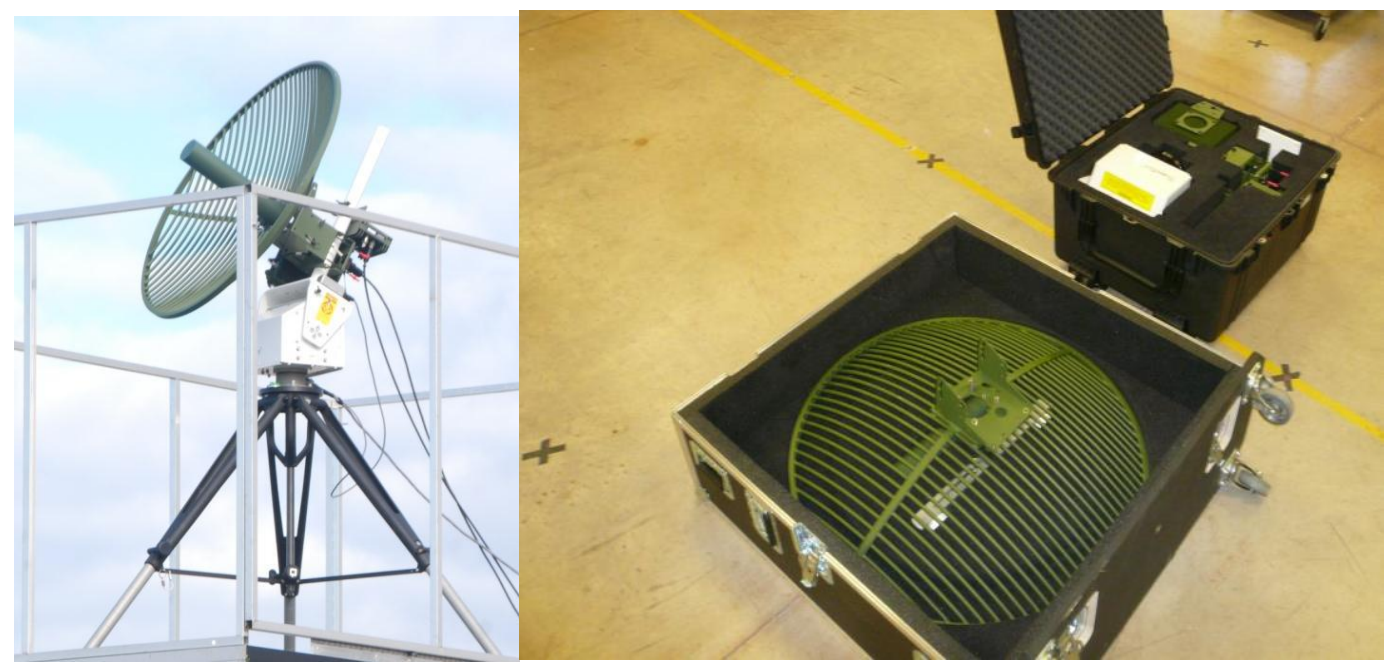

Figure 5.2. RAMS ground station antenna assembled and packed in transportable cases.

\subsubsection{Interfaces to external systems and data flow}

Currently the RAMS system operates external to Emergency Management systems. It uses best practices of making data available through web-services. These include ArcGIS Rest which integrates with ESRI GIS products, WMS which integrates with open source mapping tools, kml which integrates with Google 
products, and the ability to manually browse images. This allows jurisdictions utilizing RAMS to easily consume the data with their tools (e.g. Google Earth, ESRI). Figure 5.3 depicts all of the communications activities of the RAMS system. RAMS flight location and flight path can be viewed in Pictometry's Flight Tracker Software (Figure 5.4).

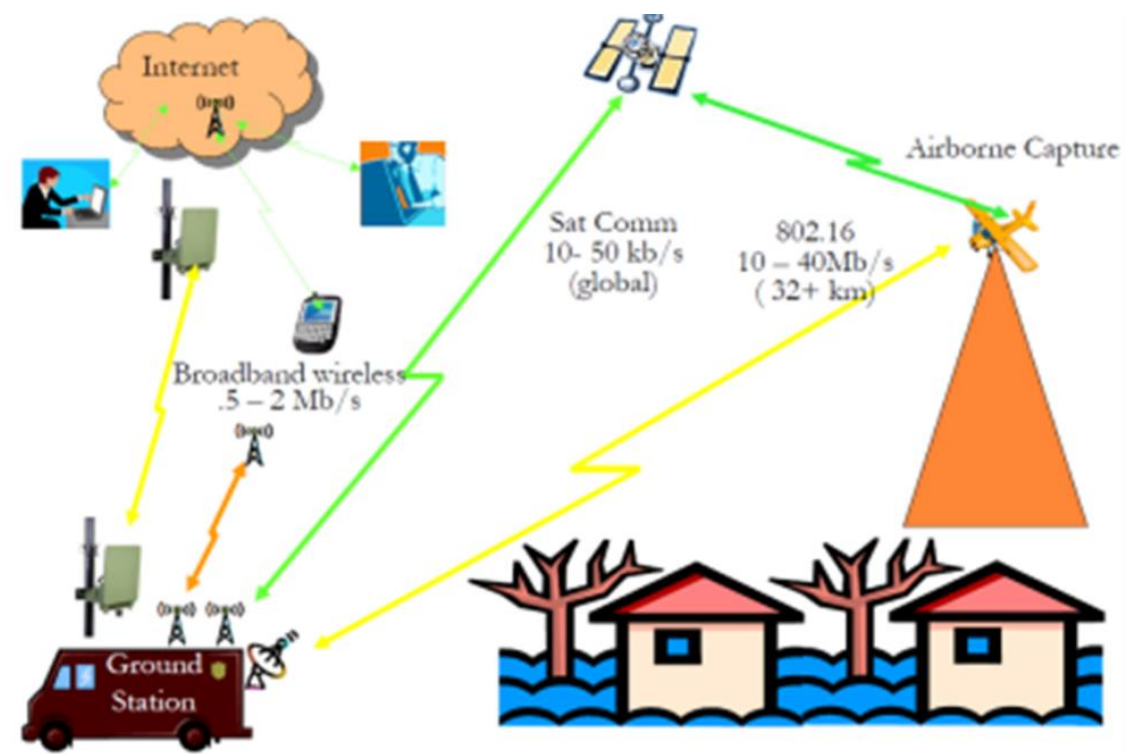

Figure 5.3. Depiction of data transfer associated with RAMS

\subsubsection{Human controls and interfaces}

RAMS has a variety of ways in which the end users can interact with the data and imagery RAMS provides. These include tools to determine status of aircraft, configure and consume RAMS feeds, and third party tools where RAMS information can be viewed and/or analyzed. The first interface is the Plane Tracker software which is accessible through a web browser (Fig. 5.4). The Plane Tracker software allows a user to view the status and location of the RAMS aircraft. This includes information such as latitude, longitude, altitude, speed, and heading. This tool is useful for estimating time until plane has reached the ROI and how far the aircrew is into the mapping assignment. 


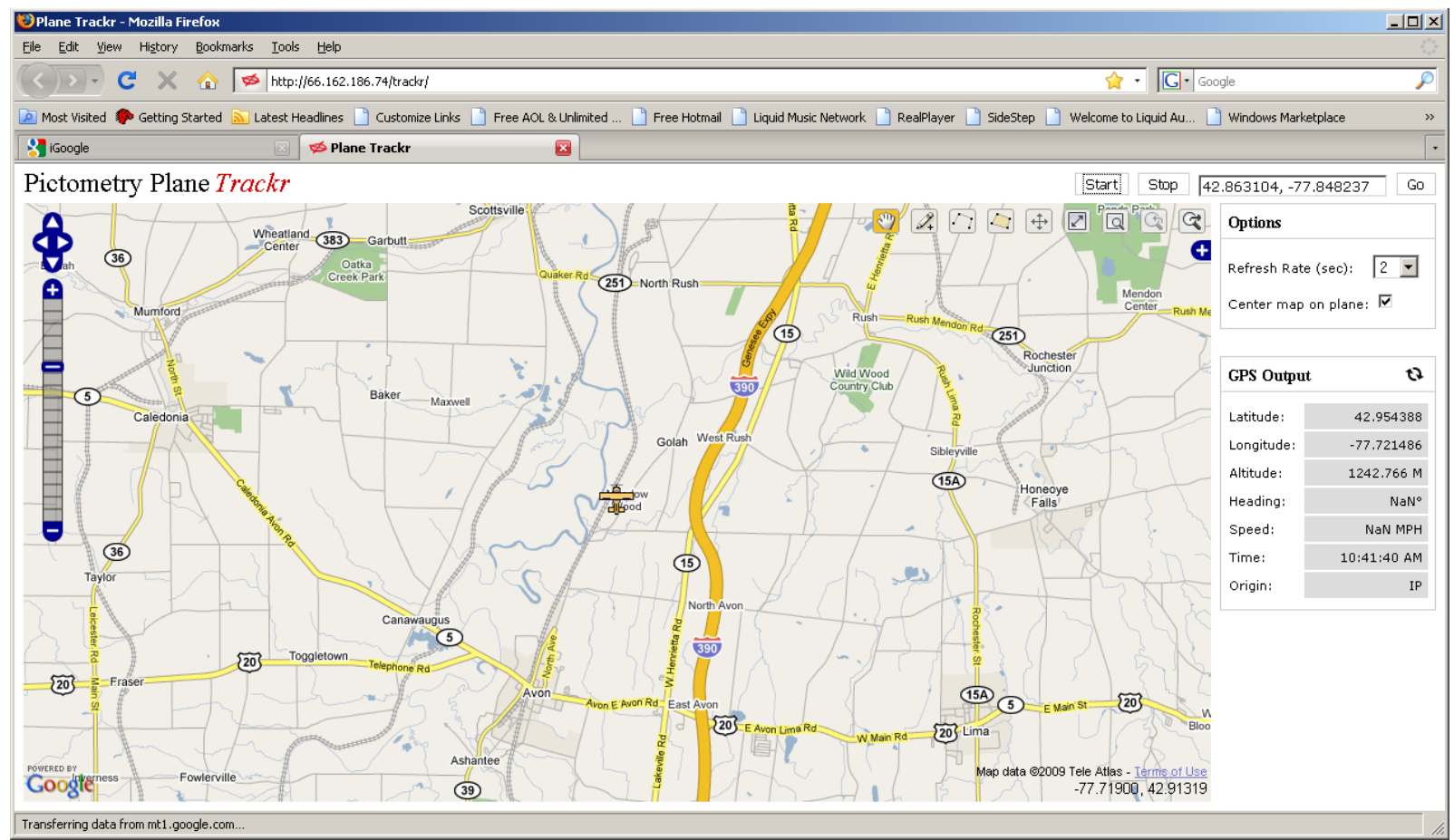

Figure 5.4. Pictometry provided Plane Tracker Software

The RAMS configuration interface is also accessed through a web browser (Fig. 5.5). This interface allows the user to configure the WMS, $\mathrm{kml}$, and rest web services for consumption. The user can also access images directly through this interface either by flight sortie or image number (Fig. 5.6).

The remainder of the end user interfaces are for consuming RAMS data and involves third party GIS software. While there are a number of tools that can consume RAMS information, this document will focus on two web-based tools: Google Earth and ESRI Flex viewer. These tools were selected for their ease of use by non-GIS experts, as the majority of the Emergency Management community falls into this category. Google Earth can either be accessed through a web browser with a Google Earth plug-in or a standalone application. Google Earth provides a simple and intuitive interface for interacting with geolocated imagery and layers. Google Earth represents the earth as a three-dimensional sphere and allows the user to rotate and zoom to a ROI (Fig. 5.7). Google Earth is divided into two primary panes. 


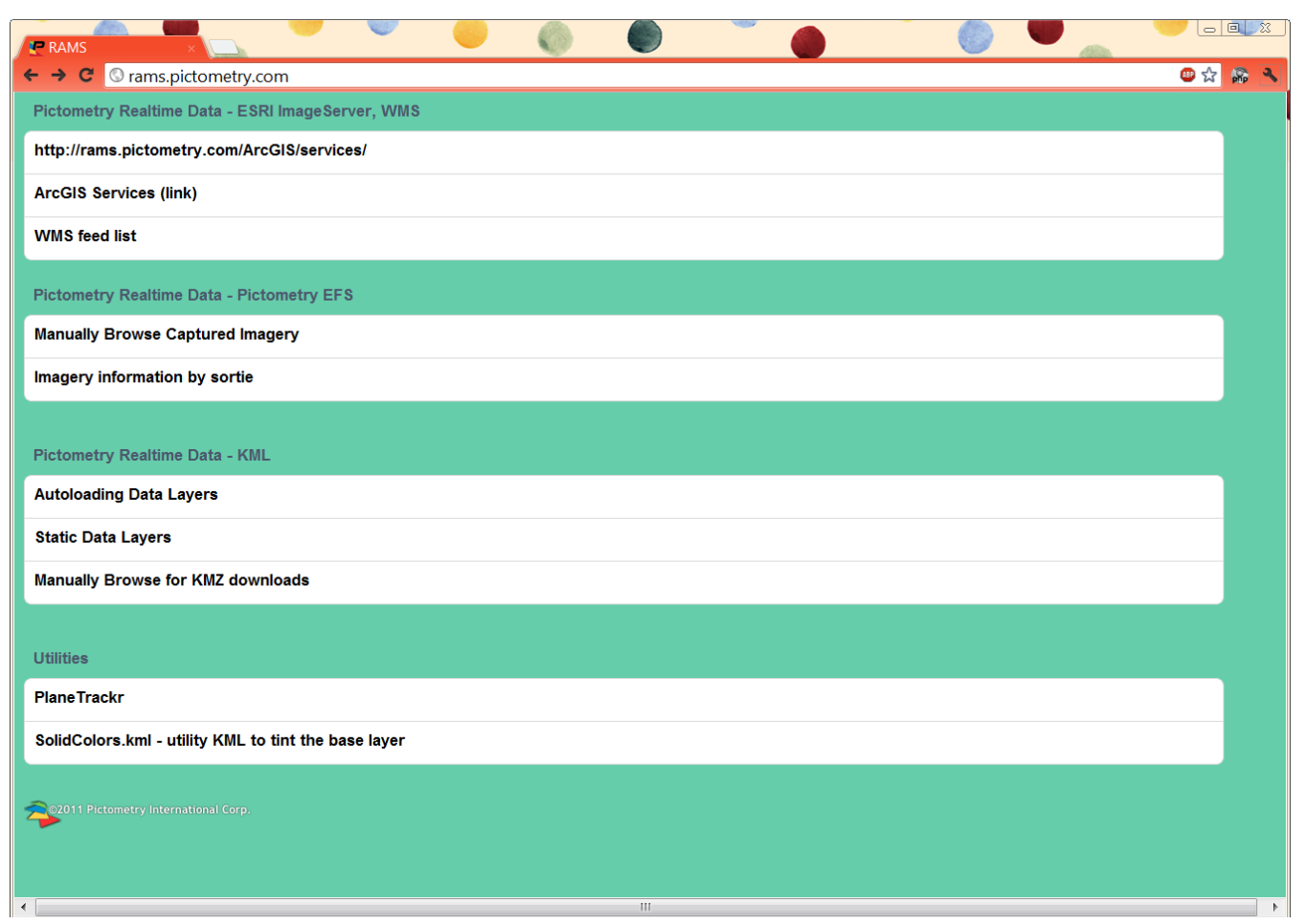

Figure 5.5. RAMS interface to select interact with RAMS data and feds.

The main pane is a view into the active layers and imagery associated with the current ROI. This pane also includes controls for navigation (pan, tilt, and zoom). The secondary pane has a location search feature and allows for the selection of active layers. These layers can contain information such as roads, places of interest, modeled plumes, and geolocated imagery. Figure 5.7 details how RAMS imagery is accessed from Google Earth. In the secondary pane a number of sorties are selected for viewing in the primary pane. These layers are displayed as colored, semi-transparent rectangles overlaid on the base map in the primary pane. Each color is associated with a unique RAMS layer, which is in turn associated with a specific RAMS flight. Clicking any individual rectangle will pop up details on the image associated with that ROI and flight. From this detail pop-up it is possible to download a high resolution nadir (Fig. 5.8) or side-looking (Fig. 5.9) image to be overlaid on the base map. 


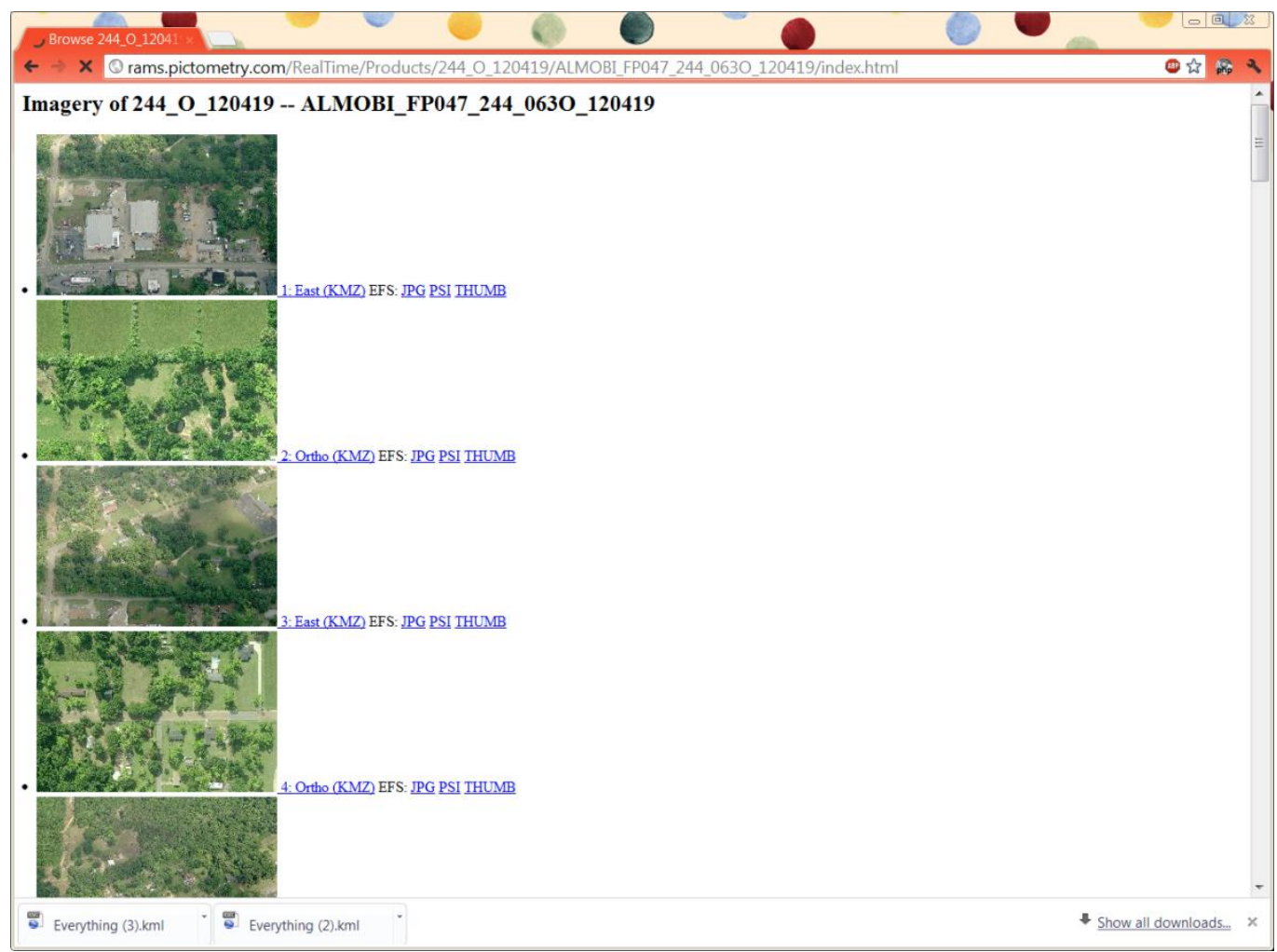

Figure 5.6. RAMS interface for manually selecting images.

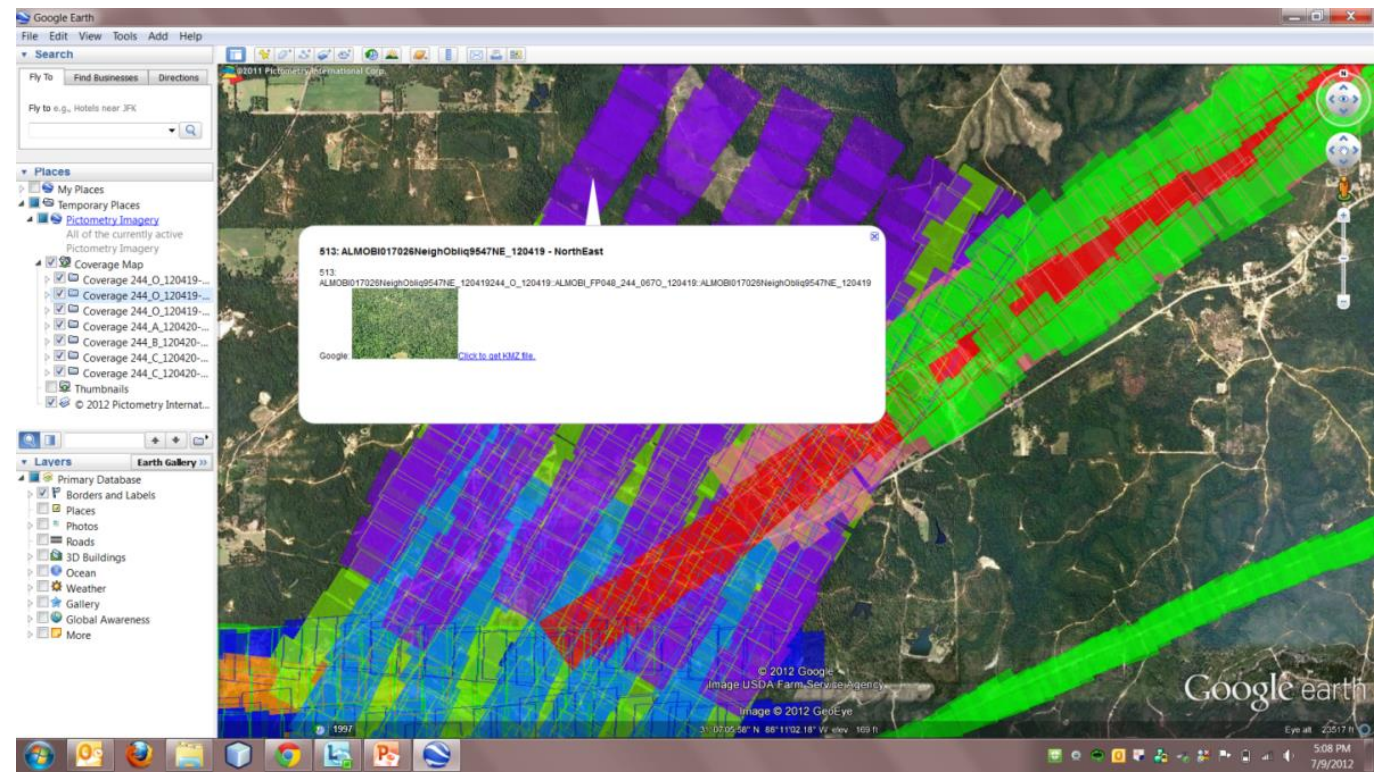

Figure 5.7. RAMS image pass coverage displayed in Google Earth. 


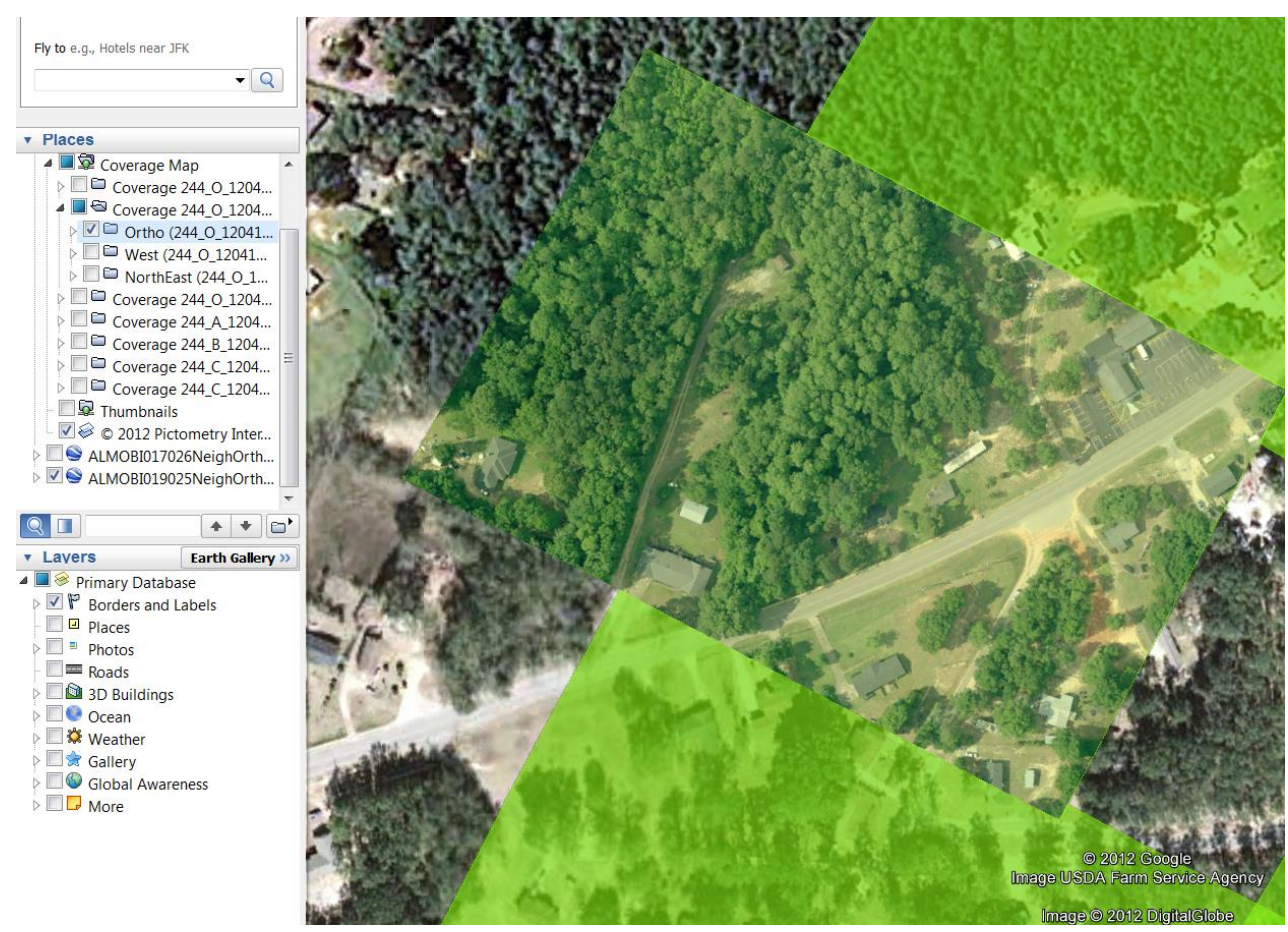

Figure 5.8. Details a RAMS ground image (center) and coverage tiles overlaid on Google Earth imagery.

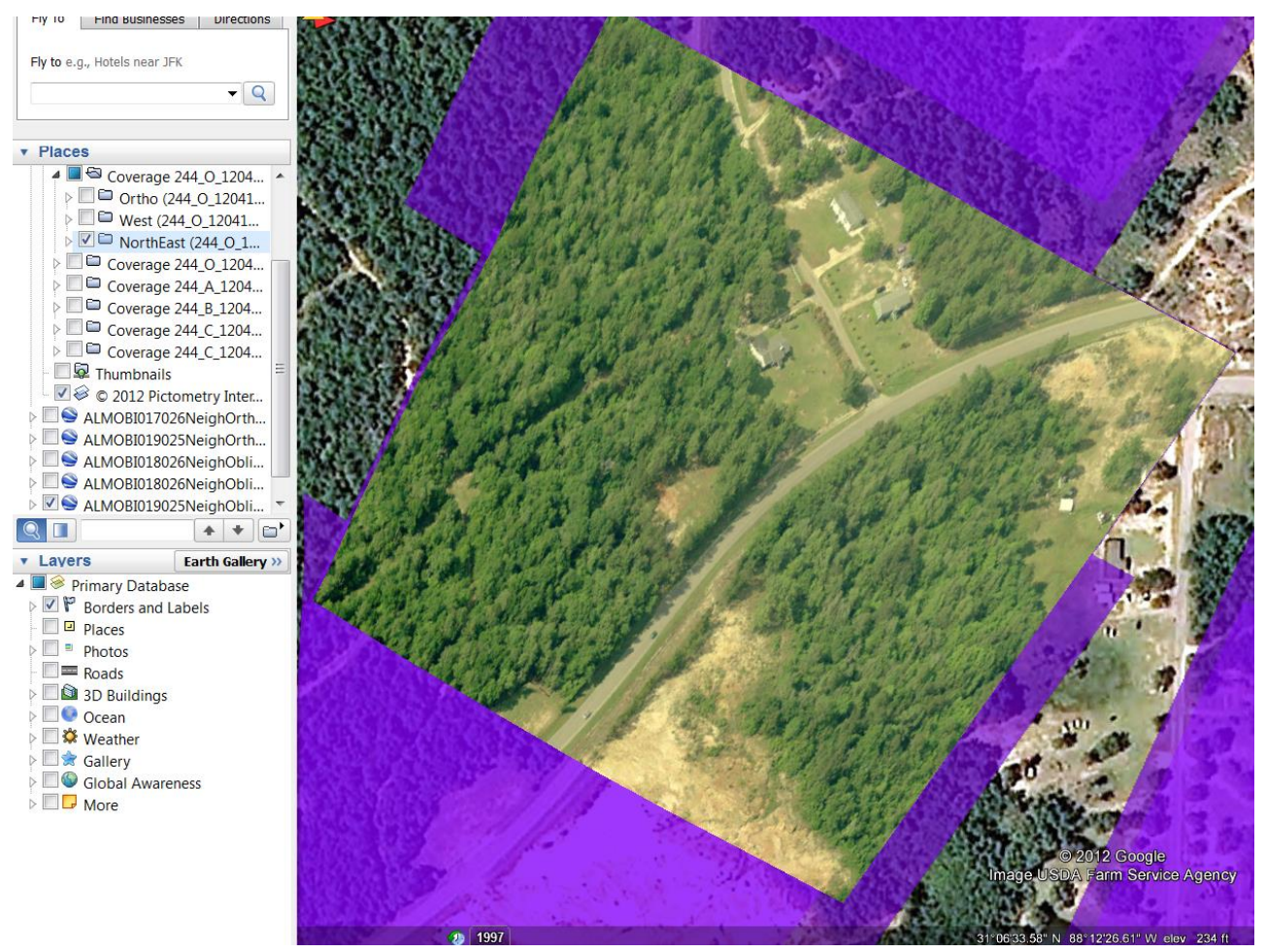

Figure 5.9. Detail of an oblique image taken with RAMS.

The other tool examined for RAMS use is the ESRI Flex viewer. This tool has only one primary screen showing the ROI and active layers. There are pop-up tools that allow for layer activation and selection (Fig. 5.10). Figure 5.10 shows a topographic base map with roads overlaid with RAMS imagery. As the user zooms into this region high resolution imagery can be examined (Fig. 5.11). 


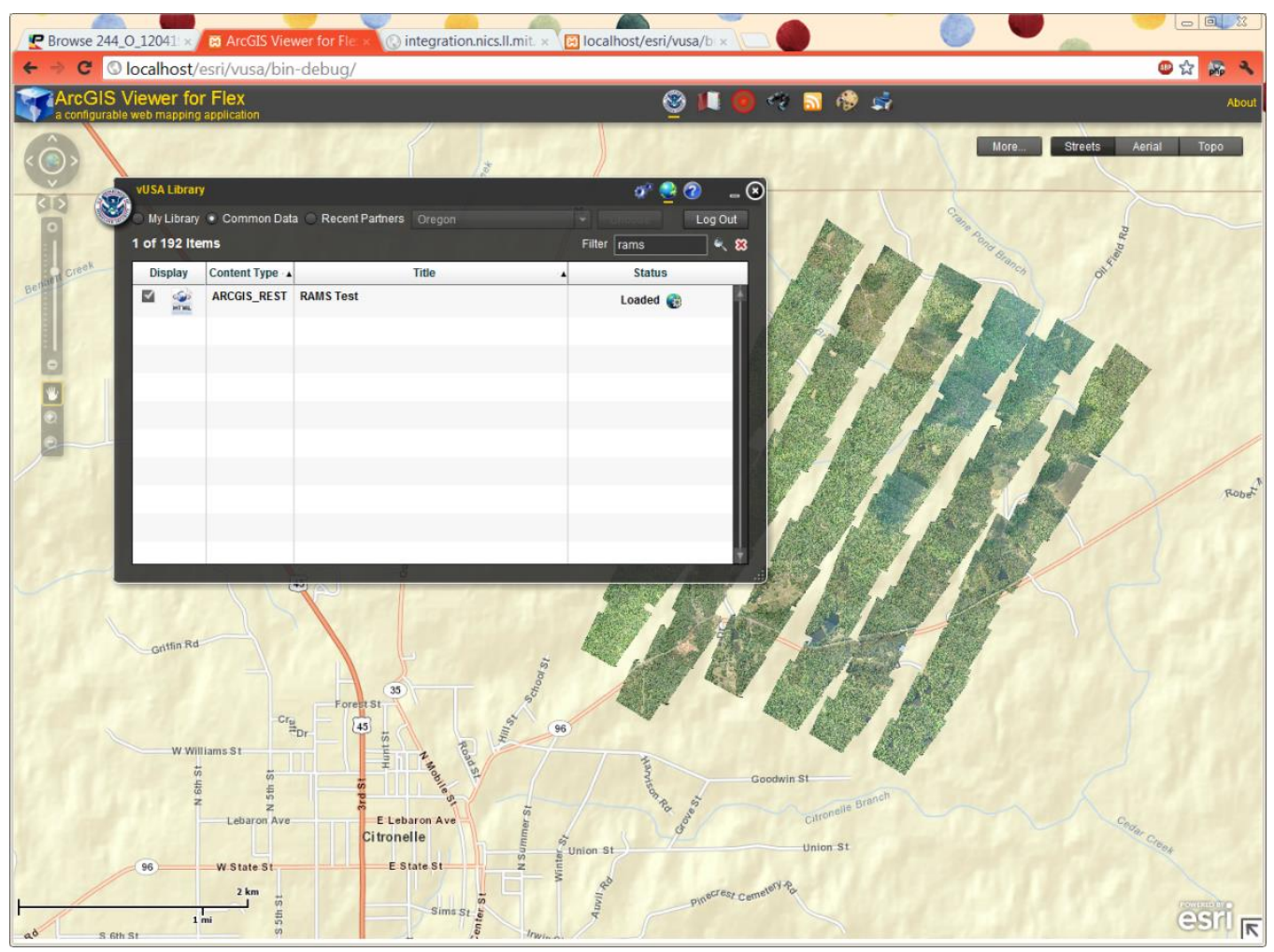

Figure 5.10. RAMS pass coverage imported into an ESRI Flex Viewer

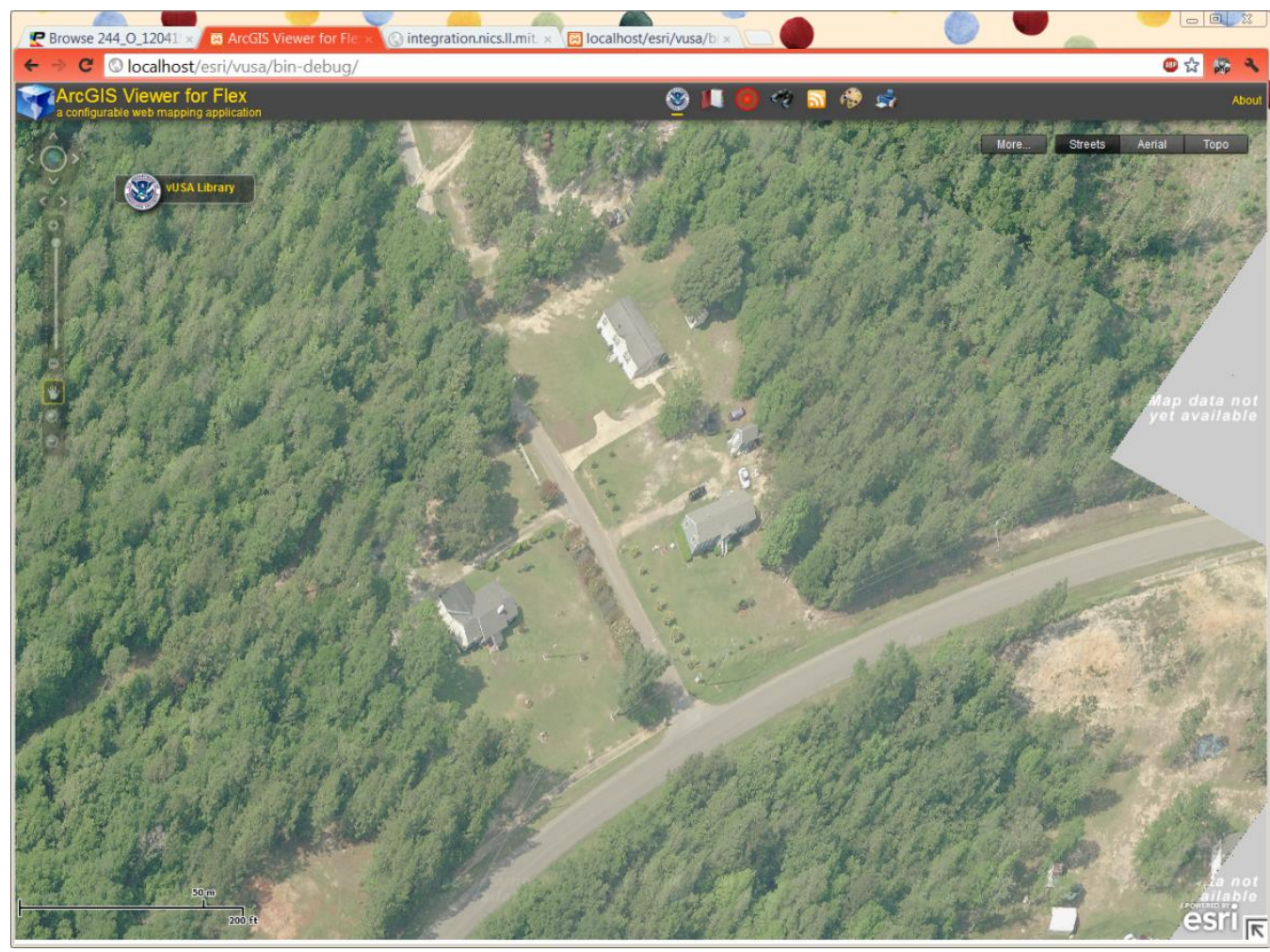

Figure 5.11. RAMS high resolution oblique image imported into an ESRI Flex Viewer. 


\subsection{Modes of Operation}

The modes of operation for the proposed system are:

- Regular

- Emergency

- Training

- Maintenance

Regular mode of operation describes the system when used strictly for data collection and not associated with a disaster event. This mode includes the capture of images for use in preparation of disaster events to maintain current (before disaster) images that can be used for comparison.

Emergency mode of operation describes the system in its intended or primary purpose. Section 6 provides detailed descriptions of this mode.

Training mode describes how the system will be used in order to test or train new users.

Maintenance mode describes how the system will be maintained and upgrades will be applied.

\subsection{User Classes and Other Involved Personnel}

\subsubsection{Organizational structure}

Organizational Structure for Fire usage including Urban Search and Rescue

- Fire Head Quarters, including Command and Control

○ Battalion

- Fire Station

- USAR Task Force

- Fire Fighters

- USAR Squad Company

- USAR Engine Company

○ Fire Fixed Wing Pilots

\section{Organizational Structure for Regional Use of RAMS}

At this time a definitive organizational structure for the use of RAMS has not been established outside of those described for urban search and rescue. However, a notional architecture is presented which has been suggested by potential stakeholders in regions outside of LA County. This structure was proposed as a method for managing cost of a RAMS system and maximizing the access to RAMS for all communities in a region.

- FEMA Region Operations

- State Emergency Operations

$\circ$ County Emergency Operations

- Fire Head Quarters, including Command and Control

- Battalion

- Fire Station

- USAR Task Force

$\circ$ Fire Fighters 
- USAR Squad Company

- USAR Engine Company

- Fire Fixed Wing Pilots

- Civil Air Patrol Head Quarters

- Civil Air Patrol Region Operations

- Civil Air Patrol Wings

- Civil Air Patrol Pilots

- National Geospatial Agency 


\subsubsection{Interactions among user classes}

\section{N-squared Diagram:}

User classes are listed in bold along the diagonal. Inputs are vertically above/below the user class. Outputs are horizontally left/right of the user class.

\begin{tabular}{|c|c|c|c|c|c|c|c|c|c|}
\hline Fire $\mathrm{HQ}$ & $\begin{array}{l}\text { Tasking, Resource } \\
\text { Status, Fire specific } \\
\text { GIS products, RAMS } \\
\text { imagery }\end{array}$ & RAMS imagery & $\begin{array}{l}\text { RAMS } \\
\text { imagery }\end{array}$ & $\begin{array}{l}\text { Tasking, NGA Sat } \\
\text { Imagery and Disaster } \\
\text { Atlas, Fire specific GIS } \\
\text { products, RAMS } \\
\text { imagery }\end{array}$ & $\begin{array}{l}\text { Tasking (Flight } \\
\text { Routes and ROIs) }\end{array}$ & & $\begin{array}{l}\text { Resource } \\
\text { Request (Sat } \\
\text { Imagery) }\end{array}$ & & $\begin{array}{l}\text { RAMS } \\
\text { Imagery and } \\
\text { video from } \\
\text { flights }\end{array}$ \\
\hline \multirow[t]{3}{*}{$\begin{array}{l}\text { Status of } \\
\text { Battalion's Area }\end{array}$} & Fire Battalion & $\begin{array}{l}\text { Tasking, } \\
\text { Resource Status }\end{array}$ & & & & & & & \\
\hline & $\begin{array}{l}\text { Status of Fire } \\
\text { Station and } \\
\text { surrounding area }\end{array}$ & Fire Station & $\begin{array}{l}\text { Tasking, } \\
\text { Resource } \\
\text { Status } \\
\end{array}$ & & & & & & \\
\hline & & $\begin{array}{l}\text { WindShield } \\
\text { Survey Data }\end{array}$ & Fire Fighter & & & & & & \\
\hline $\begin{array}{l}\text { Resource } \\
\text { Requests, Mission } \\
\text { Status } \\
\end{array}$ & & & & USAR Task Force & & & & & \\
\hline $\begin{array}{l}\text { FLIR Imagery, } \\
\text { RAMS Imagery and } \\
\text { video from flights }\end{array}$ & & & & & $\begin{array}{l}\text { Fire Fixed Wing } \\
\text { Pilots }\end{array}$ & & & & \\
\hline Social Media Feeds & & & & & & $\begin{array}{l}\text { General } \\
\text { Public }\end{array}$ & & & \\
\hline \multirow[t]{3}{*}{$\begin{array}{l}\text { NGA Sat Imagery, } \\
\text { Disaster Atlas }\end{array}$} & & & & & & & State & $\begin{array}{l}\text { Resource Request } \\
\text { (Sat Imagery) }\end{array}$ & \\
\hline & & & & & & & $\begin{array}{l}\text { NGA Sat } \\
\text { Imagery, } \\
\text { Disaster Atlas }\end{array}$ & FEMA & $\begin{array}{l}\text { Resource } \\
\text { Request (Sat } \\
\text { Imagery) }\end{array}$ \\
\hline & & & & & & & & $\begin{array}{l}\text { NGA Sat Imagery, } \\
\text { Disaster Atlas }\end{array}$ & NGA \\
\hline
\end{tabular}




\subsection{Operational Scenarios}

The following scenarios provide step by step descriptions of how the RAMS system will operate under different situations and modes. The scenarios presented will be as follows:

- Emergency Response - Initial Survey Imagery Survey

- Emergency Response - Steady State Usage for Planning and Response

\subsection{Emergency Response - Situational Awareness}

\subsubsection{Introduction}

This section describes how the RAMS technology can be incorporated into emergency management processes in response to a disaster situation. The primary benefits that RAMS provides are:

- Expediting the ability to prioritize issues and designate routes to deliver resources to areas of highest priority.

- Elevating situational awareness by rapidly providing current aerial imagery of the region including critical infrastructure and high occupancy structures that may not be visible from windshield survey routes.

- Production of base maps utilizing current aerial imagery, which makes understanding the situation at both macro and micro levels quicker and more effective.

- Improved prioritization and triage of search and rescue tasking. When combined with details from windshield surveys, requests from 911 and dispatch, requests directly to stations, and requests over radio, the RAMS imagery will provide: A) another source of information previously unavailable and B) a tool to corroborate incoming information with current images detailing situation.

Note that the RAMS ConOps described are meant to augment the applicable Standard Operating Procedures (SOPs) by enhancing situational awareness with current aerial imagery. These ConOps should not supersede or replace SOPs already in place.

The RAMS integration will be presented in two different work flows, which correspond to the initial phases of RAMS data acquisition and incorporation into emergency management responses:

Phase I - Initial Ground Imagery Survey. This phase occurs in the first 24 hours after a disaster event.

Phase 2 - Steady State Usage for Planning and Response. This phase typically starts 12 to 24 hours after a disaster event and continues until all issues have been addressed.

\subsubsection{Phase 1 - Initial Ground Imagery Survey}

When a disaster occurs, emergency personnel must rapidly establish the severity and extent of any damage and dangers to human health. This is especially challenging in the first hours after a disaster as everything is in a state of flux: conditions may still be changing (i.e., ongoing damage), staffing at emergency operations locations is limited as personnel must report in to work and have the same personal and transportation challenges as the public does, and the understanding of the situation continually changes as new reports and information is received. It is in this dynamic environment that information must be gathered and processed quickly by the available staff in order to appropriately address issues and develop tactical plans. Often initial information reports do not provide an optimal level of detail. The 
RAMS technology is intended to substantially improve the initial situational awareness and provide the information needed to assess the situation and develop plans with relatively limited personnel resources. The Phase 1 workflow is presented in Figure 6.1. A description of each of the steps is presented below. The step numbers correspond to the box numbers in Figure 6.1. 


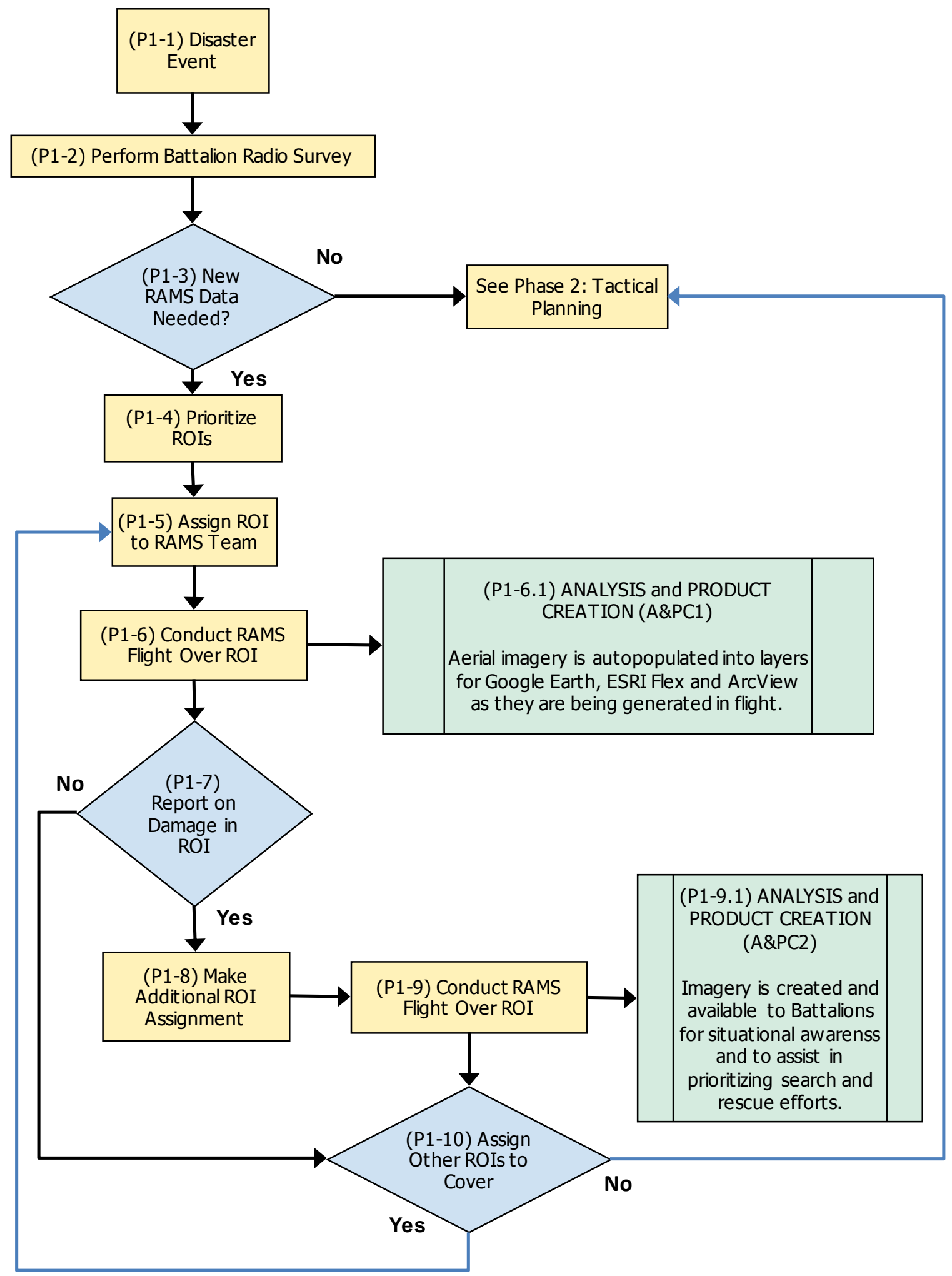

Figure 6.1. Phase 1 RAMS Integrated Workflow 
1. (P1-1) Disaster Event - This is an event that is significant enough that it requires emergency management action

2. (P1-2) Perform Battalion Radio Survey - Los Angeles County and Fire (LACoFire) performs a radio survey of all 22 Battalions. All Battalions check in and report damage in their area on a scale of 0 to 5 . This process typically takes approximately 10 minutes, but can vary depending on the scale of the event.

3. (P1-3) Decide if New RAMS Data is Needed - Make a determination of whether or not it would be valuable to collect new RAMS data based on the damage report values provided by the Battalions.

○ If any Battalions report damage at a value of 3 to 5, then proceed to Step P1-4.

$\circ$ If all Battalions report damage at values of 0,1 or 2 , then the rest of the Phase 1 activities can be skipped and Phase 2 (Tactical Planning) can be initiated. Workflow for Phase 2 is provided in Section 3.

4. (P1-4) Prioritize ROIs - Command and Control (C\&C) prioritizes flight regions of interest (ROI) areas based on Battalion reports and other issues reported. This includes any previously designated infrastructure, critical assets, or other high priority areas within the battalion area.

5. (P1-5) Define and Assign ROI to RAMS Team - C\&C selects a ROI and ensures that the flight area include access routes (i.e., routes to move resources). $\mathrm{C} \& \mathrm{C}$ communicates the details to the flight team and instructs the team to fly RAMS over the ROI.

6. (P1-6) Conduct RAMS Flight Over ROI - Flight team concurrently covers ROI, captures images and transmits images for use in base maps and analysis.

6.1 (P1-6.1) Analysis and Product Creation 1 (A\&PC1) - Aerial imagery is auto populated into layers for Google Earth, ESRI Flex and ArcView as they are being generated in flight. $\mathrm{C} \& \mathrm{C}$ or planning personnel utilize new aerial imagery layer with road layers to determine best route to deliver resources. This can be conveyed over radio or visually with mapbased tools (Web based: ESRI Flex tools, Google Earth and/or Local: ESRI ArcView to PDF or JPG). Any critical infrastructure and buildings of interest are also overlaid in ROI maps.

7. (P1-7) Report On Damage in ROI - RAMS flight team indicates if there are any major structures or critical infrastructures in the current ROI or flight path that are damaged. The next step is dependent on the answer as follows:

$\circ$ If there is obvious damage to major or critical structures, then proceed to Step 8 (P1-8).

$\circ$ If there is no obvious damage to a major structure, then skip to Step 10 (P1-10).

8. (P1-8) Make Additional ROI Assignment - If there is obvious damage to a major or critical structure, the $\mathrm{C} \& \mathrm{C}$ will select a ROI around the structure. $\mathrm{C} \& \mathrm{C}$ communicates the details to the flight team and instructs the team to fly RAMS over the new ROI. 
9. (P1-9) Conduct RAMS Flight Over new ROI - Flight team covers ROI, captures images and transmits images for use in base maps and analysis.

9.1 (P1-9.1) Analysis and Product Creation 2 (A\&PC2) - Imagery is created and available to Battalions for situational awareness and to supplement their windshield surveys and to assist in prioritizing search and rescue efforts. (Phase 2 Tactical Planning). Methods for creation follow methods from A\&PC1.

10. (P1-10) Assign Other ROIs to Cover - C\&C indicates if there are any other Battalions that have indicated high levels of damage. The next step is dependent on the answer as follows:

$\circ$ If the answer is 'NO', then Phase 2 can be initiated. Workflow for Phase 2 is provided in Section 3.

- If the answer is 'YES', then cycle back to Step P1-4. The C\&C will assign the next highest Battalion ROI to survey.

\subsubsection{Phase 2 - Steady state Usage for Planning and Response, including urban search and rescue.}

As noted previously, the Tactical Planning and Response phase is typically initiated 12 to 24 hours after a disaster event, when situational awareness has been effectively established and fire stations are adequately staffed. Information gathered and processed in Phase 1 is used to inform decision making, develop plans of action, and execute the response to the disaster.

The Phase 2 workflow is presented in Figures 6.2 and 6.3. Figure 6.2 diagrams the work flow associated with prioritizing assignments (Steps P2-1 through P2-9) and Figure 6.3 diagrams the work flow associated with executing assignments (Steps P2-10 through P2-18). A description of each of the steps is presented below. The step numbers correspond to the box numbers in Figures 6.2 and 6.3. 


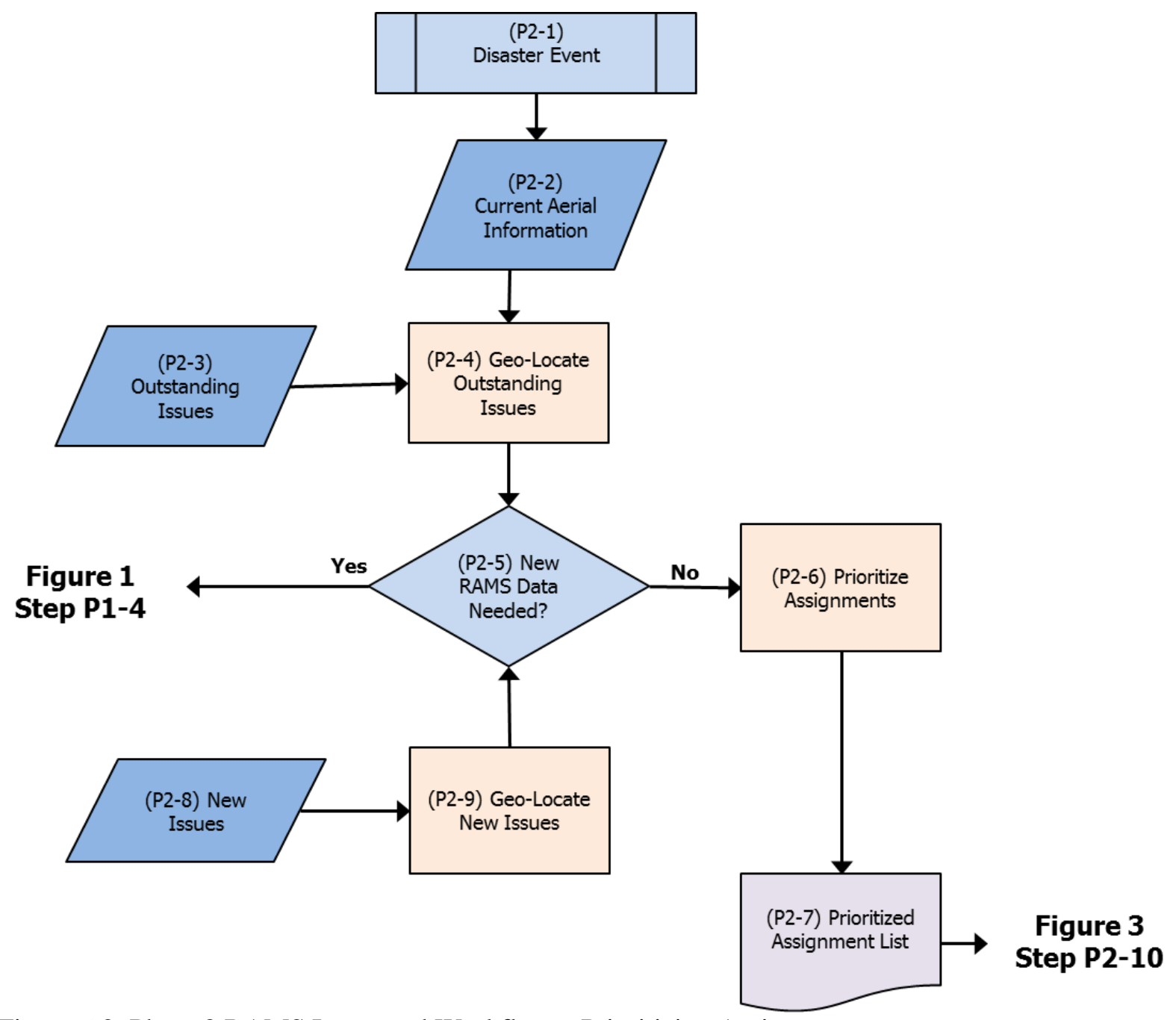

Figure 6.2. Phase 2 RAMS Integrated Workflow - Prioritizing Assignments 


\section{Figure 2 \\ Step P2-7}

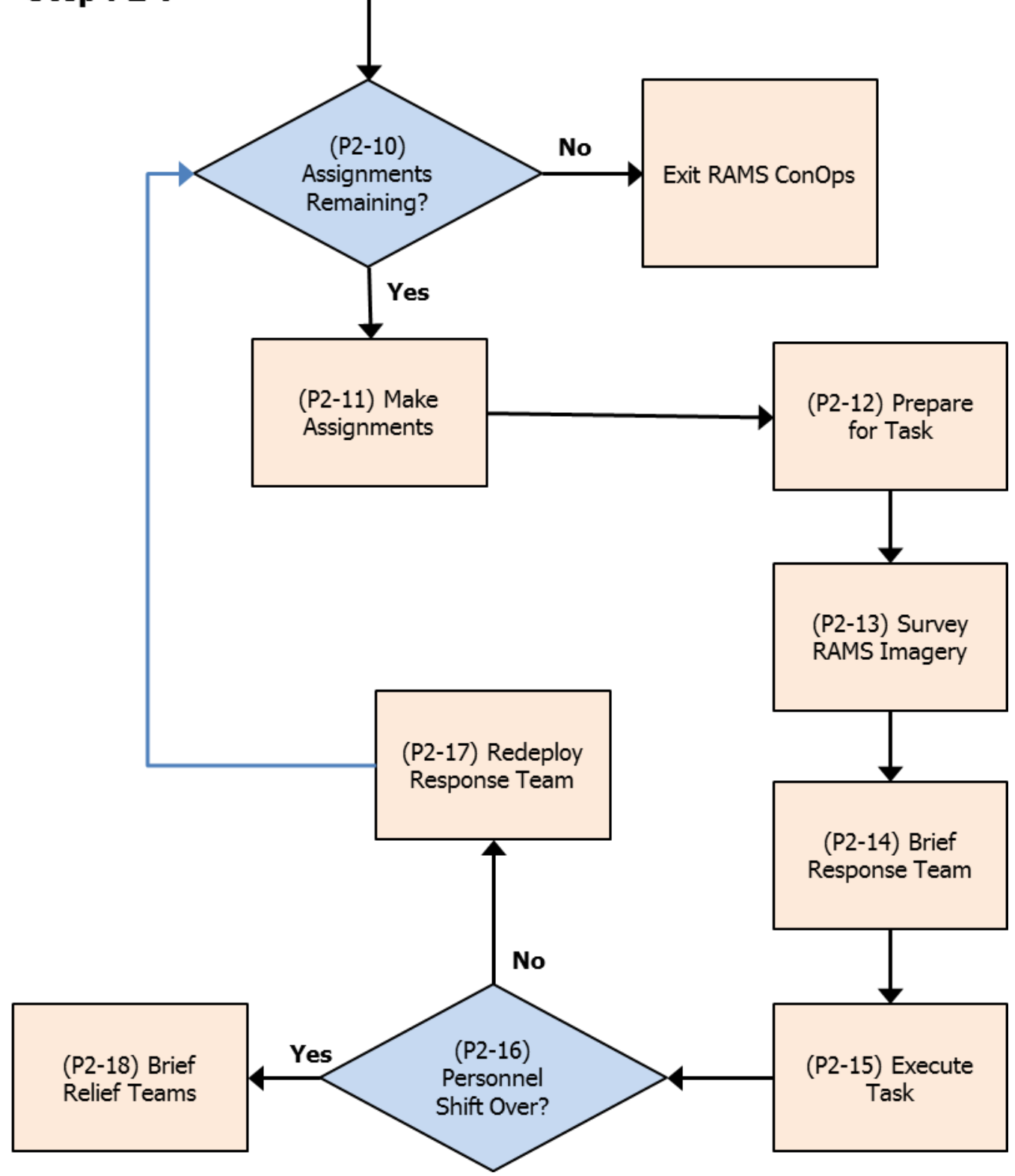

Figure 6.3. Phase 2 RAMS Integrated Workflow - Executing Assignments

1. (P2-1) Disaster Event - It has likely been 12 to 24 hours after event has occurred. Phase 1 has been completed, which includes radio surveys of battalions; initial windshield surveys; preliminary resource routes determined and routing information is available; and all Phase 1 postevent aerial imagery around roads, critical infrastructure, and high occupancy structures is available. Staff that would be active at this level would be the Planners at the C\&C, trained staff at the battalion or station level, and Dispatchers.

2. (P2-2) Current Aerial Information - Layers created in Phase 1 (A\&PC1 and A\&PC2) or in follow on requests are accessed. Layers include: open roads, closed roads, geolocated damage assessment from windshield survey. 
3. (P2-3) Outstanding Issues - List of outstanding existing assignments compiled of issues that have occurred since event began from 911, other dispatch assignments, calls direct to station, etc...

4. (P2-4) Geo-Locate Outstanding Issues - Outstanding assignments are located on a RAMS enabled map and imagery is used as additional input to validate details of assignments and provide additional information for fire captain or battalion chief to use in prioritization of issues.

5. (P2-5) New RAMS Data Needed? - For each issue, an evaluation is made as to the existence and adequacy of the aerial imagery that is available to address the planning associated with the issue. Actions resulting from this decision are as follows:

- If the current imagery is available and sufficient for an issue, then it is ready to be moved to the Prioritize Assignments step (Step P2-6).

- If the imagery is not available, current, and/or does not provide sufficient information for planning to address an issue, a request will be made to obtain new RAMS imagery. The steps outlined in Phase 1 would be followed again starting at Step P1-4. New layers created in either step A\&PC1 or A\&PC2 would made available for Phase 2 Step P2-2. Even if new RAMS imagery is needed, the issue will be moved to Step P2-6 for prioritization. As new imagery is available, it will be pushed to personnel planning and executing the assignment.

6. (P2-6) Prioritize Assignments - Initially this list will be comprised of outstanding issues that need to be addressed but as issues continue to be received, their priority needs to be evaluated and properly placed in the Assignment List.

7. (P2-7) Prioritized Assignment List - This list will initially be comprised of outstanding issues that need to be addressed but will also be continually updated and modified as new issues are reported. This step leads directly into Step P2-10 - Assign Tasks.

8. (P2-8) New Issues - Throughout the day, new issues are reported via 911, other dispatch assignments, and calls directly to the station. Other issues are discovered based on newly acquired RAMS imagery.

9. (P2-9) Geo-Locate New Issues - Incoming assignments are located or reviewed on a RAMS enabled map and imagery is used as additional input to validate details of new assignments and gives additional information for fire captains or battalion chiefs to use in prioritization. This step feeds back into Step P2-5 where a determination is made as to whether new RAMS data is needed. [Step occurs each time a new assignment needs to be prioritized]

10. (P2-10) Assignments Remaining? - At this step in the process, a check will be made to determine if there are any assignments remaining to be performed. Actions resulting from this decision are as follows: 
If there are no more assignments, then exit the RAMS ConOps

$\circ$ If there are assignments remaining, then assignments will be made to the appropriate response teams (Step P2-11).

11. P2-11 Make Assignments - Fire personnel (including Search and Rescue Teams) are tasked with assignments based on priority by Battalion Chief or Fire Captain.

12. P2-12 Prepare for Task - Response personnel examine RAMS imagery prior to arriving on site. This process is intended to: 1) enable better situational awareness by giving both visual details of the scene, 2) provide time for personnel to process the environment in which they will be working and 3) plan an approach to accomplish task safely and effectively.

13. P2-13 Survey RAMS Imagery - Personnel examine the task location and surrounding vicinity with most recent RAMS imagery to ensure understanding of access routes and possible hazards to the response team.

14. P2-14 Brief Response Team - Personnel brief the response team on hazards and determine best way to accomplish task while mitigating hazards determined from onsite survey and surrounding area via RAMS imagery.

15. P2-15 Execute and Complete Task - Response team executes tasks

16. P2-16 Personnel Shift Over? - Determine if response team personnel are relieved of duty for this shift after completion of task? Actions resulting from this decision are as follows:

- If the response team shift is not over, then the team is re-deployed. Continue to Step P217.

- If the response team shift is over, then precede with shift change procedures. Continue to Step P2-18.

17. P2-17 Redeploy Response Team - Verify that there are assignments remaining. Cycle back to Step P2-10.

18. P2-18 Brief Relief Teams - Utilize RAMS imagery, describe current situation and recent activities to the response team started the next shift. 


\subsection{Summary of Impacts}

\subsection{Operational Impacts}

It is anticipated that RAMS usage would easily integrate with current operations. It would require that pilots and aircraft fly routes to obtain imagery with RAMS. This would mean that these pilots and aircraft would not be available for other missions including obtaining aerial video and FLIR imagery unless the ROI for those missions were identical to that for the RAMS mission. GIS technicians would also be required to ensure that RAMS imagery was being properly consumed and displayed in various viewers.

\subsection{Organizational Impacts}

Organizational structure for all involved parties is not expected to change as a result of the adoption of RAMS by any single agency. There are potential impacts if RAMS was a shared asset utilized by multiple agencies. The type and scale of impacts would be determined by the structure adopted.

\subsection{Analysis of the Proposed System}

\subsection{Summary of Improvements}

\section{Improvements:}

- Ground imagery available in near real-time for consumption by end users and GIS

- Ability to update base map images and oblique images on demand

- Ability to utilize post-disaster imagery for situational awareness soon after the event

- Ability to utilize post-disaster imagery for prioritization and analysis soon after the event

- Ability to provide rapid, defendable damage assessments to support emergency declarations

\subsection{Disadvantages and Limitations}

While RAMS provides some very useful capabilities to bare for emergency response, it is important understand the limitations of the system.

\section{Limitations:}

- If environmental conditions are not suitable for takeoff RAMS will not be available for operations

- RAMS utilizes visible range digital cameras and will be of limited use in low light conditions (e.g. night)

- Low clouds will limit RAMS from having a reasonable field of view and therefore limit its utility.

- Ground environment is also critical for capturing information on the ground. Fog and smoke in the ROI will limit utility for RAMS. 
- Line of sight with mobile base station is required for RAMS to have real-time delivery of imagery. This can be difficult in disasters where road infrastructure is damaged.

- Proprietary systems have the potential for problems when it comes to maintenance (e.g. replacement parts availability, software updates) 